\title{
BMJ Open Effects of female genital cutting on physical health outcomes: a systematic review and meta-analysis
}

\author{
Rigmor C Berg, Vigdis Underland, Jan Odgaard-Jensen, Atle Fretheim, \\ Gunn E Vist
}

To cite: Berg RC, Underland V, OdgaardJensen $\mathrm{J}$, et al. Effects of female genital cutting on physical health outcomes: a systematic review and metaanalysis. BMJ Open 2014;4: e006316. doi:10.1136/ bmjopen-2014-006316

- Prepublication history and additional material is available. To view please visit the journal (http://dx.doi.org/ 10.1136/bmjopen-2014006316).

Received 6 August 2014 Revised 27 October 2014 Accepted 29 October 2014

CrossMark

Norwegian Knowledge Center for the Health Services, Oslo, Norway

Correspondence to Dr Rigmor C Berg; rigmor.berg@nokc.no

\section{ABSTRACT}

Objective: Worldwide, an estimated 125 million girls and women live with female genital mutilation/cutting (FGM/C). We aimed to systematically review the evidence for physical health risks associated with $\mathrm{FGM} / \mathrm{C}$.

Design: We searched 15 databases to identify studies (up to January 2012). Selection criteria were empirical studies reporting physical health outcomes from FGM/ $\mathrm{C}$, affecting females with any type of FGM/C, irrespective of ethnicity, nationality and age. Two review authors independently screened titles and abstracts, applied eligibility criteria, assessed methodological study quality and extracted full-text data. To derive overall risk estimates, we combined data from included studies using the Mantel-Haenszel method for unadjusted dichotomous data and the generic inverse-variance method for adjusted data. Outcomes that were sufficiently similar across studies and reasonably resistant to biases were aggregated in meta-analyses. We applied the instrument Grading of Recommendations Assessment, Development and Evaluation to assess the extent to which we have confidence in the effect estimates.

Results: Our search returned 5109 results, of which 185 studies (3.17 million women) satisfied the inclusion criteria. The risks of systematic and random errors were variable and we focused on key outcomes from the 57 studies with the best available evidence. The most common immediate complications were excessive bleeding, urine retention and genital tissue swelling. The most valid and statistically significant associations for the physical health sequelae of FGM/C were seen on urinary tract infections (unadjusted $\mathrm{RR}=3.01$ ), bacterial vaginosis (adjusted $\mathrm{OR}(\mathrm{AOR})$ $=1.68)$, dyspareunia $(R R=1.53)$, prolonged labour $(A O R=1.49)$, caesarean section ( $A O R=1.60)$, and difficult delivery ( $A O R=1.88)$.

Conclusions: While the precise estimation of the frequency and risk of immediate, gynaecological, sexual and obstetric complications is not possible, the results weigh against the continuation of FGM/C and support the diagnosis and management of girls and women suffering the physical risks of $\mathrm{FGM} / \mathrm{C}$.

Trial registration number: This study is registered with PROSPERO, number CRD42012003321.
Strengths and limitations of this study

- Based on the studies in this systematic review, there is clear evidence that female genital mutilation/cutting (FGM/C) entails harms to women's physical health throughout their life, from the moment of cutting as an infant or child, to sexuality and childbirth in adulthood.

- The precise estimation of the frequency and risk of complications was not feasible because of the small sample sizes and varying methods of the studies.

- However, the consistency of results with increased risk of several physical harms in women with genital modification is robust.

- Therefore, efforts should be expended in safeguarding girls and women against the physical risks of $F G M / C$ and caring for those who suffer from its consequences.

\section{INTRODUCTION}

The centuries-old practice of female genital mutilation/cutting (FGM/C), also known as female circumcision, is a culturally sanctioned practice ${ }^{12}$ that consists of "all procedures involving partial or total removal of the female external genitalia or other injury to the female genital organs for non-medical reasons." According to the WHO typology, there are three main types: type I (clitoridectomy), type II (excision), type III (infibulation or pharaonic circumcision), and type IV, which is used to describe all other harmful procedures to the female genitalia in the absence of medical necessity. ${ }^{1}$ Types I-III and unaltered external female genitalia are depicted in figure 1 . The nomenclature for the practice varies across regions, ideological perspectives and research frames, and we use the expression preferred by UNICEF and UNFPA, two central policymakers in the global effort to end the practice, 'female genital mutilation/cutting' (FGM/C). ${ }^{2}$ Wade explains that Western efforts to end FGM/C since the early 1970 s has relied primarily on 

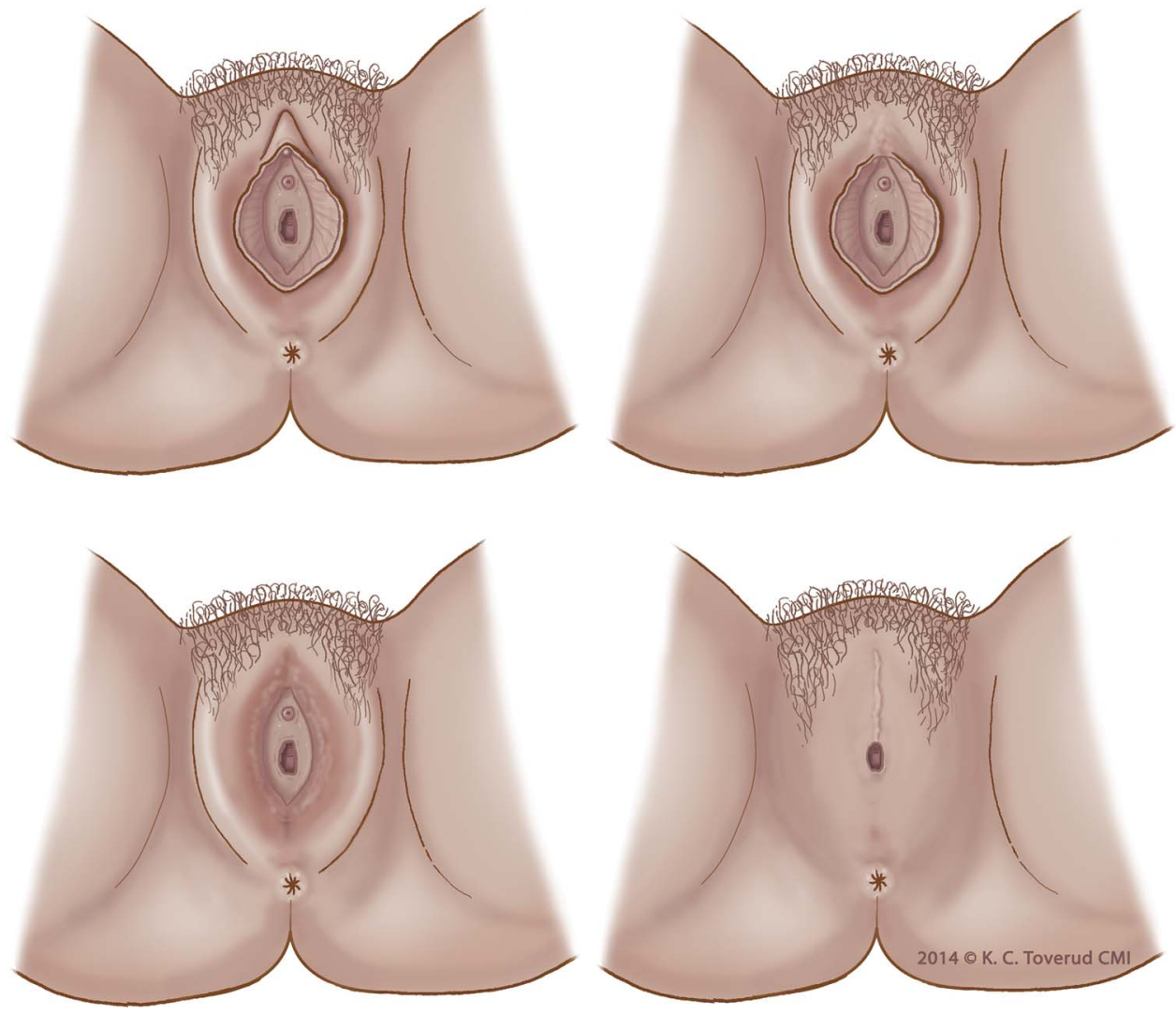

Figure 1 Illustration of unaltered external female genitalia and female genital mutilation/cutting (FGM/C) types I-III. From top left: unaltered external female genitalia, type I (clitoridectomy), type II (excision) and type III (infibulation).

two frames that have influenced the discourse of FGM/C and, in turn, the ideological contestation over the practice. ${ }^{3}$ In addition to the women's right frame, a dominant frame has been that the practice involves physical and mental harm.

Indeed, for close to a century, observational studies, supported by biological theories, have suggested a negative association between $\mathrm{FGM} / \mathrm{C}$ and various health outcomes. Such studies have been summarised in a handful of reviews. Epidemiologist and medical anthropologist Obermeyer first reviewed and critiqued the available literature on FGM/C until 1996, and next summarised the subsequent literature from 1997 to $2002 .^{4}{ }^{5}$ Another early review examined primary data on health complications after FGM/C with particular emphasis on sequelae in childbirth. ${ }^{6}$ Recently, Iavazzo et al's review explored the clinical evidence for an association between FGM/C and infections. The first systematic review in this fieldaddressing the social, psychological and sexual consequences of FGM/C-critically reviewed and extracted data and analysed 17 comparative studies. ${ }^{8}{ }^{9}$ While much of this research suggests a harmful effect of FGM/ C on women's health, the findings from observational studies and non-systematic reviews are equivocal. Additionally, some commentators have questioned the evidence for many of the claimed short-term and longterm medical consequences of FGM/C, such as quality of sex life, obstetric complications and infections. ${ }^{10}$
We aimed to systematically review the evidence for the range of physical health risks associated with FGM/C by summarising the findings from three technical systematic review reports detailing the association. ${ }^{11-13}$

\section{METHODS}

We conducted a systematic review of the physical health risks and consequences of female genital modification in accordance with the Cochrane Handbook for Systematic Reviews of Interventions and PRISMA (Preferred Reporting Items for Systematic reviews and meta-Analyses) guidelines, ${ }^{14}{ }^{15}$ using a predetermined protocol (PROSPERO, number CRD42012001915). The full details of the systematic review including the search strategies, risk of bias assessment and analysis are found in three technical reports. ${ }^{11-13}$

\section{Search strategy}

The search strategy was developed and undertaken by an experienced search specialist. Fifteen international electronic literature databases were searched to identify research published between inception and January 2012, with Medical Subject Headings descriptors and keywords such as infibulation, applying neither methodology search filters nor language or other search restrictions. The search strategy for MEDLINE (Ovid MEDLINE In-Process \& Other Non-Indexed Citations 1946 to 20 January 2012) is shown: 
1. Circumcision, Female/

2. ((female $\$$ or wom\#n or girl\$1) adj3 (mutilation\$ or circumcis $\$$ or cutting $\$)$ ).tw.

3. "fgm/c".tw.

4. ((removal\$ or alteration\$ or excision $\$)$ adj6 female genital\$).tw.

5. pharaonic circumcision\$.tw.

6. sunna.tw.

7. (clitoridectom\$ or clitorectom\$).tw.

8. (infibulat $\$$ or reinfibulat $\$$ or deinfibulat $\$$ ).tw.

9. or $/ 1-8$

One reviewer (RCB) manually screened the bibliographies of published reviews on FGM/C and all included studies for additional qualifying studies. RCB did additional searches for the relevant grey literature and unpublished studies in OpenGrey, OpenSigle, OAIster, browsed websites of six international organisations that are engaged in projects regarding FGM/C, and communicated with experts in the field.

\section{Selection of studies and extraction of data}

Studies retrieved were eligible for inclusion if they satisfied all our criteria: Be an empirical quantitative study with or without a comparison group published in any language that presented original quantitative data for physical health outcomes in women who had undergone any type of FGM/C as defined by the WHO. ${ }^{1}$ All physical health outcomes were eligible, including but not limited to death, infections, infertility, fistula, pain, urinary complications, shock (primary outcomes), and bleeding/haemorrhage, menstrual complications, obstetric complications, vaginal calculus formation, cysts, tissue injury, fractured/displaced bones, urethral meatal stenosis/ urethral stricture, abscesses, keloid and other scarring (secondary outcomes). We applied the following exclusion criteria: Qualitative studies, studies without a quantitative measure of a physical consequence of FGM/C, and all genital modifications not captured by the WHO stated FGM/C definition.

Screening, quality appraisal and data extraction were independently undertaken by two investigators (RCB and $\mathrm{VU}$ ), with discrepancies resolved by consensus. The two investigators confirmed the eligibility of first titles and abstracts and then full texts. Quality assessment of the identified studies was undertaken as recommended in the Cochrane Handbook, using design specific checklists based on the User's Guide framework. ${ }^{16}$ This was done at the study level. The investigators extracted study information and data onto a standardised data collection form, which had been piloted. Data extracted included publication details, study design, sample characteristics, FGM/C characteristics, methods of outcome measurement and health consequences. We contacted authors for additional data or clarification where needed.

\section{Statistical analysis}

We grouped the data according to outcomes across the studies, keeping the outcome categories or labels as reported in each individual study. We estimated associations for dichotomous unadjusted variables in terms of relative risks (RR) with $95 \%$ CIs. ORs and 95\% CIs were used for case-control studies and adjusted analyses. Outcomes that were sufficiently similar across studies, and reasonable resistant to biases and relatively homogeneous in this respect, were aggregated in meta-analyses. When available, we pooled adjusted estimates; otherwise, we pooled the unadjusted estimates based on crude data from the individual studies. ORs and RRs greater than one indicate an increased risk of complications with FGM/C; if less than one, they indicate a decreased risk.

We anticipated heterogeneity between studies due to different study methodologies and geographical and population differences. Heterogeneity was examined using the $\chi^{2}$ test and $\mathrm{I}^{2}$ statistic. We used a randomeffects model to account for within-study and betweenstudy heterogeneity.

In random-effects meta-analysis, the weight assigned to each included study is adjusted to include a measure of variation $\left(\tau^{2}\right)$ in the effects reported between studies. We used the Mantel-Haenszel method for unadjusted dichotomous data, and for adjusted data we used the generic inverse-variance method, in which weight is given to each study according to the inverse of the variance of the effect, to minimise uncertainty about the pooled effect estimates. Analyses were done with Review Manager (V.5.2.8).

We applied the instrument Grading of Recommendations Assessment, Development and Evaluation (GRADE) to assess the extent to which we have confidence in the effect estimates. ${ }^{17}$ GRADE is a transparent and systematic approach to grading our confidence in the evidence. For resource reasons, we used GRADE only for outcomes eligible for meta-analysis.

Those of us who did the systematic review were not masked to the authors, institution or journal of publication. The use of non-masked reviewers is accepted practice in meta-analyses and has been shown not to bias results. ${ }^{18}$ In line with recommendations, ${ }^{14}$ results from the studies deemed to have the highest internal validity were given preference. In this communication, we present all studies that reported outcomes for differentially FGM/C exposed groups of women, that is, studies with a comparison group.

\section{Role of the funding source}

Norad and the WHO commissioned the study and the latter contributed some funding $(\$ 10000)$. The commissioners of the systematic review had no role in the study design, data collection, data analysis, data interpretation or writing of the report. RCB had final responsibility for the decision to submit for publication.

\section{RESULTS}

Our search strategy identified 5109 unique publications, the titles and abstracts of which were screened for 
inclusion. The full text of 12 publications could not be located, while 431 articles were retrieved, of which 185 met the inclusion criteria (figure 2).

The 185 included studies were of varying publication types, published between 1927 and 2011, and from 42 different countries (see online supplementary appendix 1). There were 13 studies from the Middle East, 43 from a Western country, and 129 from Africa. Twenty different African countries were represented. The FGM/C participants in studies from a Western country originated in the majority of cases from Somalia, and in the remaining cases they originated from another African country where FGM/C is commonly practised. Overall, the 185 studies involved 3.17 million female participants, from infants to women in their $70 \mathrm{~s}$, with a mean age of approximately 30. With respect to the FGM/C characteristics, the majority of women had genital alteration that involved the cutting and removal of portions of the external female genitalia, without stitching, corresponding to either type I or type II. The procedure had in the absolute majority of cases been undertaken in early childhood, usually before the age of 10 , by a traditional circumciser. A total of 75 different outcomes were extracted.

In this overview, we present key physical health complications of FGM/C in a life course perspective. Except for some immediate outcomes, these key outcomes derive from comparative studies, that is, women with FGM/C are compared to women without FGM/C with respect to an outcome in a cohort, case-control or crosssectional study (table 1). We prioritise the presentation of studies with clinically measured and adjusted outcome data, but note also the best available evidence for additional key outcomes, largely immediate complications. Table 1 shows the 57 studies with the best available evidence regarding the physical health sequelae of FGM/C (comparative cohort, case-control, crosssectional studies).${ }^{19-72}$ About $40 \%$ of the outcomes were self-reported primarily by adult women, although the great majority of the obstetric and some genitourinary outcomes were clinically measured. The meta-analytical results that are based on unadjusted estimates are presented in figure 3, and those based on adjusted estimates are shown in figure 4 .

\section{Immediate complications}

In most cases of FGM/C, a girl's clitoris and labia are cut away, often with a crude unsterile instrument and without anaesthetics by a traditional practitioner who has little knowledge of female anatomy. ${ }^{2}$ Thus, it is reasonable to assume that physiological harms such as bleeding ensue during the cutting process and the shortterm postprocedure period. We identified no studies that analysed the potential statistical differences in the risk of direct, procedure-related complications between types of FGM/C. However, 56 observational studies reported on eight main types of immediate medical harms (bleeding, shock, genital tissue swelling, fever, infections and problems with urination and wound healing) on 133515 females of various ages and types of FGM/C. The rate of immediate complications varied greatly across the studies. There were strong indications of under-reporting of immediate complications from the procedure, with some studies reporting that $90 \%$ of the girls undergoing FGM/C experienced no bleeding at all. ${ }^{30}{ }^{64}$ However, representative studies (ie, where the participants can be assumed to represent the larger population) of moderate and high methodological quality indicated that the most common immediate

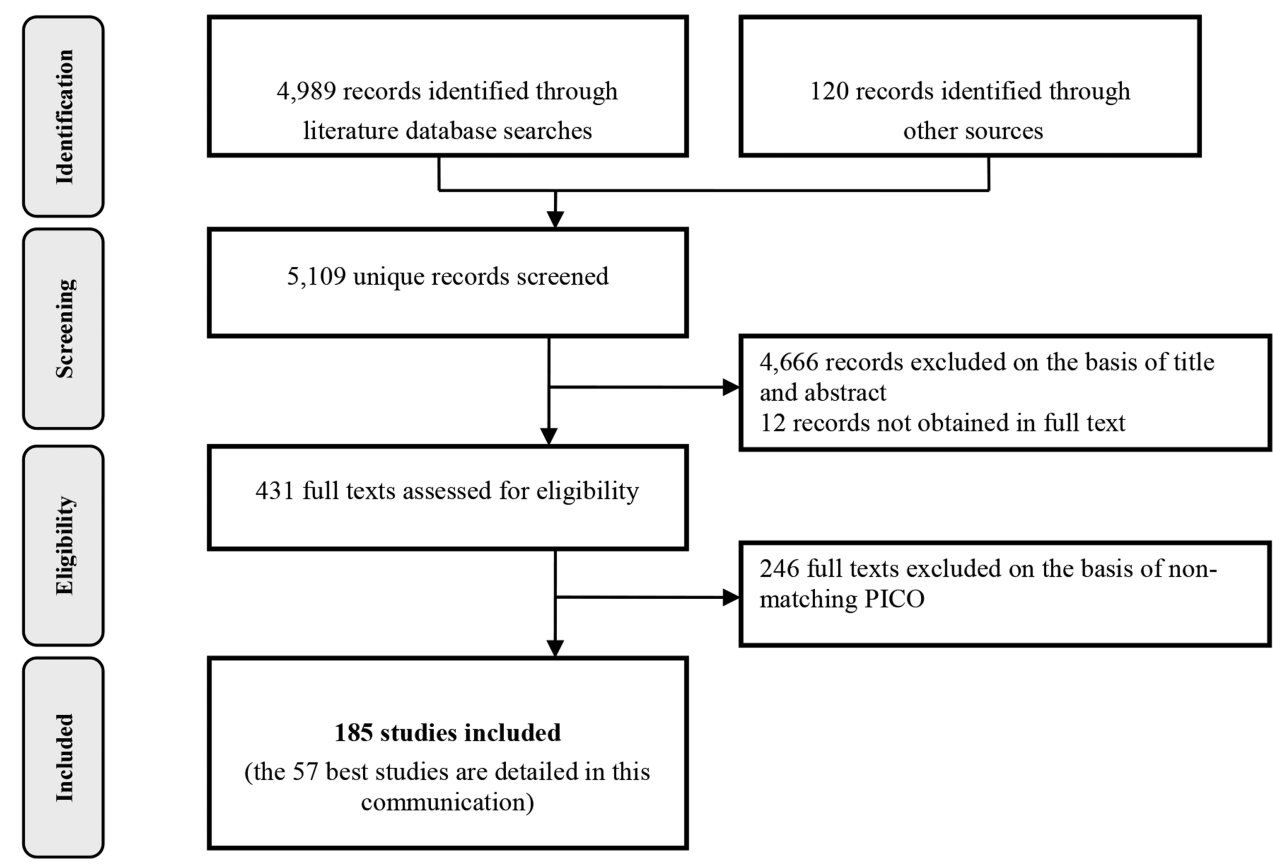

Figure 2 PRISMA flow diagram for selection of literature. 
Table 1 Summary of included comparative studies $(\mathrm{N}=57)$

\begin{tabular}{|c|c|c|c|c|c|}
\hline Author, year & Study design & Quality & $\mathbf{N}$ & Country & Outcomes (assessment type) \\
\hline Adinma, $1997^{19}$ & Cross-sectional & Low & 256 & Nigeria & Obstetric (self-report) \\
\hline Almroth, $2005 a^{20}$ & Case-control & High & 279 & Sudan & Infertility (clinical) \\
\hline Almroth, $2005 b^{21}$ & Cross-sectional & High & 255 & Sudan & Genitourinary (clinical) \\
\hline Alsibiani, $2010^{22}$ & Cross-sectional & Moderate & 260 & Saudi Arabia & Sexual (self-report) \\
\hline Balk, $2000^{23}$ & $\begin{array}{l}\text { Based on the Sudan DHS } \\
1990\end{array}$ & Moderate & 5856 & Sudan & Infertility (self-report) \\
\hline Berardi, $1985^{24}$ & Prospective & Low & 852 & France & Obstetric (clinical) \\
\hline Bohoussou, $1986^{25}$ & Cross-sectional & Low & 4935 & Ivory Coast & Obstetric (unclear) \\
\hline Brewer, $2007^{26}$ & $\begin{array}{l}\text { Based on the Kenya DHS } \\
2003\end{array}$ & High & 539 & Kenya & HIV/STIs (clinical) \\
\hline Browning, $2010^{27}$ & Retrospective cohort & Moderate & 492 & Ethiopia & Genitourinary, obstetric (clinical) \\
\hline Chibber, $2011^{28}$ & Prospective & Low & 4800 & Unclear & Obstetric (clinical) \\
\hline De Silva, $1989^{29}$ & Prospective & Low & 2157 & Saudi Arabia & Genitourinary, obstetric (clinical) \\
\hline El Dareer, $1983^{30}$ & Cross-sectional & Low & 3210 & Sudan & $\begin{array}{l}\text { Immediate, genitourinary } \\
\text { (self-report) }\end{array}$ \\
\hline el Defrawi, $2001^{31}$ & Cross-sectional & Moderate & 250 & Egypt & $\begin{array}{l}\text { Genitourinary, sexual } \\
\text { (self-report) }\end{array}$ \\
\hline Elmusharaf, $2006^{32}$ & Case-control & High & 222 & Sudan & HIV/STIs (clinical) \\
\hline Elnashar, $2007^{33}$ & Cross-sectional & Low & 264 & Egypt & $\begin{array}{l}\text { Genitourinary, sexual, obstetric, } \\
\text { (self-report) }\end{array}$ \\
\hline Essén, $2005^{36}$ & Registry study & Moderate & 2554 & Sweden & Obstetric (clinical) \\
\hline Fillo, $2007^{37}$ & $\begin{array}{l}\text { Based on the Burkina } \\
\text { Faso DHS } 2003\end{array}$ & Moderate & 12477 & Burkina Faso & Genitourinary (unclear) \\
\hline Hakim, $2001^{38}$ & $\begin{array}{l}\text { Unclear if prospective or } \\
\text { retrospective }\end{array}$ & Low & 1481 & Ethiopia & Obstetric (clinical) \\
\hline Holmgren, $2003^{39}$ & Cross-sectional & Moderate & 857 & Guinea-Bissau & HIV/STIs (clinical) \\
\hline Inhorn, $1993^{40}$ & Case-control & High & 190 & Egypt & Infertility (clinical) \\
\hline Jackson, $2005^{41}$ & Cross-sectional & Low & $?$ & Ghana & Infertility (self-report) \\
\hline Johnson $2005^{42}$ & Registry study & Low & 5416 & USA & Obstetric (clinical) \\
\hline Jones, $1999-I^{43}$ & Cross-sectional & Low & 1920 & Burkina Faso & $\begin{array}{l}\text { Genitourinary (clinical), obstetric } \\
\text { (self-report) }\end{array}$ \\
\hline Jones, 1999-II 43 & Prospective & Moderate & 5337 & Mali & Genitourinary, obstetric (clinical) \\
\hline Kanki, $1992^{44}$ & Cross-sectional & Moderate & 1710 & Senegal & HIV/STIs (clinical) \\
\hline Kaplan, $2011^{45}$ & Cross-sectional & Moderate & 871 & Gambia & $\begin{array}{l}\text { Immediate (self-report), } \\
\text { genitourinary (clinical) }\end{array}$ \\
\hline Klouman, $2005^{46}$ & Cross-sectional & Moderate & 396 & Tanzania & $\begin{array}{l}\text { Genitourinary, HIV/STIs, } \\
\text { infertility (clinical) }\end{array}$ \\
\hline Larsen, $2002^{47}$ & $\begin{array}{l}\text { Based on the Sudan DHS } \\
1990\end{array}$ & Moderate & 5849 & Sudan & Infertility (self-report) \\
\hline Larsen $2002^{48}$ & Cross-sectional & Low & 1836 & Nigeria & Obstetric (self-report) \\
\hline Larsen, 2000-1 ${ }^{49}$ & $\begin{array}{l}\text { Based on the CAR DHS } \\
1995\end{array}$ & Moderate & 4388 & $\begin{array}{l}\text { Central African } \\
\text { Republic }\end{array}$ & Infertility (self-report) \\
\hline Larsen, 2000-1I ${ }^{49}$ & $\begin{array}{l}\text { Based on the Ivory Coast } \\
\text { DHS } 1995\end{array}$ & Moderate & 5930 & Ivory Coast & Infertility (self-report) \\
\hline Larsen, 2000-III ${ }^{49}$ & $\begin{array}{l}\text { Based on the Tanzania } \\
\text { DHS } 1997\end{array}$ & Moderate & 6043 & Tanzania & Infertility (self-report) \\
\hline Larsen, $1989^{50}$ & Cross-sectional & Low & 2183 & Sudan & Infertility (self-report) \\
\hline Lupo, $1999^{51}$ & Registry study & Low & 114 & USA & Obstetric (unclear) \\
\hline $\begin{array}{l}\text { Maslovskaya, } \\
2009^{52}\end{array}$ & $\begin{array}{l}\text { Based on the Kenya DHS } \\
2003\end{array}$ & High & 3114 & Kenya & HIV/STIs (clinical) \\
\hline $\begin{array}{l}\text { Millogo-Traore, } \\
2007^{53}\end{array}$ & Prospective & Low & 454 & Burkina Faso & Obstetric (clinical) \\
\hline Morison, $2001^{54}$ & Cross-sectional & High & 1157 & Gambia & $\begin{array}{l}\text { Genitourinary, sexual, HIV/STIs, } \\
\text { infertility (clinical) }\end{array}$ \\
\hline Msuya, $2002^{55}$ & Cross-sectional & High & 379 & Tanzania & Genitourinary, HIV/STIs (clinical) \\
\hline Ndiaye, $2010^{56}$ & Cross-sectional & Low & 354 & Burkina Faso & Obstetric (clinical) \\
\hline NSEO, $2002^{34}$ & Cross-sectional & Low & 7765 & Eritrea & Sexual, obstetric (self-report) \\
\hline NSO, $1995^{35}$ & Cross-sectional & Low & 4775 & Eritrea & Sexual, obstetric (self-report) \\
\hline
\end{tabular}


Table 1 Continued

\begin{tabular}{|c|c|c|c|c|c|}
\hline Author, year & Study design & Quality & $\mathbf{N}$ & Country & Outcomes (assessment type) \\
\hline Nwajei, $2003^{57}$ & Cross-sectional & Low & 400 & Nigeria & Genitourinary (self-report) \\
\hline Odoi, $1997^{58}$ & Cross-sectional & Low & 195 & Ghana & Sexual (self-report) \\
\hline Oduro, $2006^{59}$ & Registry study & High & 5071 & Ghana & Obstetric (clinical) \\
\hline Okonofua, $2002^{60}$ & Cross-sectional & Moderate & 1836 & Nigeria & $\begin{array}{l}\text { Genitourinary, sexual (clinical/ } \\
\text { self-report) }\end{array}$ \\
\hline Orji, $2006^{61}$ & Cross-sectional & Low & 500 & Nigeria & Obstetric (self-report) \\
\hline Pépin, $2006^{62}$ & Cross-sectional & Moderate & 1026 & Guinea-Bissau & HIV (clinical) \\
\hline Pépin, $1991^{63}$ & Cross-sectional & Low & 345 & Gambia & HIV (clinical) \\
\hline Rushwan, $1983^{64}$ & Cross-sectional & Low & 2502 & Sudan & $\begin{array}{l}\text { Immediate, genitourinary, sexual, } \\
\text { infertility (self-report) }\end{array}$ \\
\hline Shandall, $1967^{65}$ & Cross-sectional & Low & 4487 & Sudan & $\begin{array}{l}\text { Immediate, genitourinary } \\
\text { (clinical/self-report) }\end{array}$ \\
\hline Slanger, $2002^{66}$ & Cross-sectional & Moderate & 1107 & Nigeria & Obstetric (self-report) \\
\hline Small, $2008^{67}$ & Registry study & Low & 2179322 & Multiple & Obstetric (clinical) \\
\hline Vangen, $2002^{68}$ & Registry study & Low & 703925 & Norway & Obstetric (clinical) \\
\hline $\begin{array}{l}\text { WHO study group, } \\
2006^{69}\end{array}$ & Prospective & High & 28393 & Multiple & Obstetric (clinical) \\
\hline Wuest, $2009^{70}$ & Prospective & Low & 232 & Switzerland & Obstetric (clinical) \\
\hline Yount, $2007^{71}$ & $\begin{array}{l}\text { Based on the Kenya DHS } \\
2003\end{array}$ & Moderate & 3167 & Kenya & $\begin{array}{l}\text { HIV/STIs (clinical), obstetric } \\
\text { (self-report) }\end{array}$ \\
\hline Yount, $2006^{72}$ & Cross-sectional & Low & 1700 & Egypt & Infertility, obstetric (self-report) \\
\hline
\end{tabular}

complications were: excessive bleeding (median 32\%, range $5-62 \%$ ), urine retention (median $31 \%$, range $8-53 \%$ ), genital tissue swelling (median 15\%, range $2-27 \%)$, problems with wound healing (13\%) and pain $(11 \%) .^{30} 7374$ Girls generally suffered more than one immediate complication. We identified three clinical reports on deaths directly attributed to FGM/C. ${ }^{75-77}$ Fourteen studies reported the number of events for different types of FGM/C separately, allowing us to estimate differences in risk across exposure groups. ${ }^{30} 45646578-87$ Our results indicated that there might be a greater risk of immediate harms with FGM/C type III relative to types I-II. We found few, and small, differences in risk of immediate complications with FGM/C types I-II compared to type IV (generally 'nick').

\section{Genitourinary problems}

With respect to the genitourinary sequelae of FGM/C, reported years and sometimes decades following the procedure, we identified 17 comparative studies. $^{21} 2729-33 \quad 37434546545557606465$ In total, the studies included 38390 women. The most frequently measured outcomes were genital tissue damage, vaginal discharge and itching, urological complications and infections. Many sequelae were examined in only one or a few studies and/or they were relatively rare events, such as keloids and abscesses. Analyses were thus often unable to establish whether there were statistically significant differences between the groups being compared and the CIs were wide. As a result, there was insufficient information available from the studies to assess difference in risk relative to $\mathrm{FGM} / \mathrm{C}$ exposure. The results were inconclusive with respect to: scarring, keloids, abscesses, fistulae, damaged tissue (perineum, anal sphincter), disfigurement, vaginal obstruction and cysts.

According to four cross-sectional studies ( $n=3657)$, there was a trend for a greater risk of vaginal discharge and itching with FGM/C (adjusted ORs (AOR) from 0.94 to 2.81). ${ }^{33} 545760$ Urological long-term complications were reported in four comparative studies $(n=3611)$, none of which could establish a statistically significant difference, either in unadjusted analyses (RRs from 0.85 to 1.78 ) or in adjusted analyses (AORs from 0.80 to 1.29 ), between women with $\mathrm{FGM} / \mathrm{C}$ and women with no FGM/C. ${ }^{27} 335460$ However, results from two studies of moderate to high methodological study quality indicated a trend for a greater risk of burning or painful urination with $\mathrm{FGM} / \mathrm{C}$ ( $\mathrm{RR}=2.56$, 95\% CI 0.80 to 8.22; $\mathrm{RR}=1.66$, $95 \%$ CI 0.96 to 2.85$).^{33} 60$ Menstrual problems were reported in five studies $(n=6564) . \begin{array}{lllll}30 & 31 & 33 & 54 & 64\end{array}$ They showed a trend towards a greater risk of menstrual problems with $\mathrm{FGM} / \mathrm{C}$ : dysmenorrhoea $(\mathrm{RR}=1.44,95 \% \mathrm{CI}$ 1.11 to 1.86$)$, difficulty in menstruation ( $\mathrm{RR}=1.02,95 \%$ CI 0.06 to 16.28$)$, menstrual problems $(\mathrm{RR}=0.77,95 \% \mathrm{CI}$ 0.61 to 0.97$)$, irregular menses $(\mathrm{RR}=2.56,95 \% \mathrm{CI} 1.48$ to $3.45)$ and difficulty in passing menstrual blood $(\mathrm{RR}=1.75$, $95 \%$ CI 0.78 to 3.93 ).

Ten comparative studies $(n=28940)$ reported results concerning long-term genitourinary infections. $^{21} 293037434654556465$ Owing to few studies and 


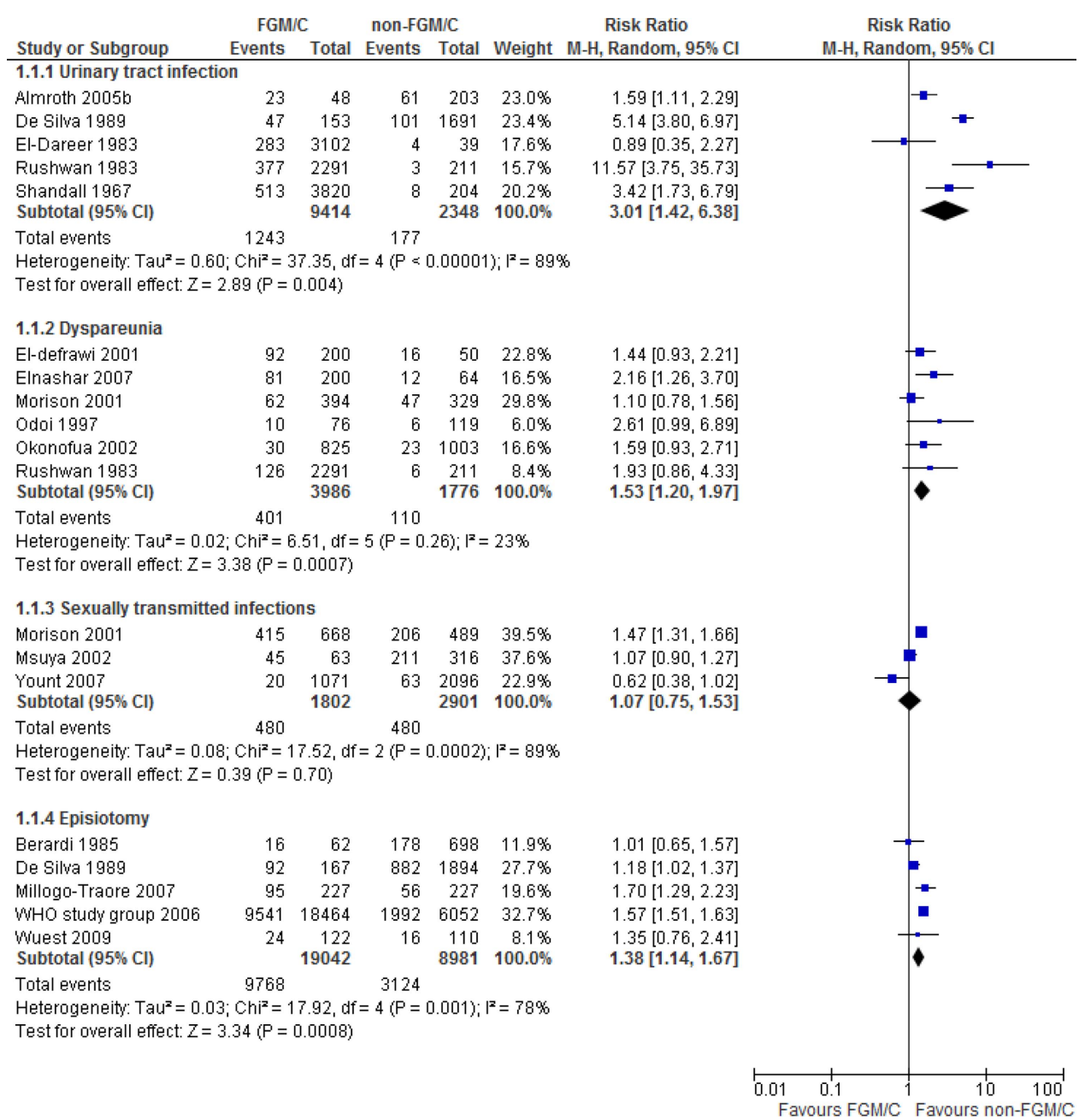

Figure 3 Meta-analyses of urinary tract infection, dyspareunia, sexually transmitted infections, episiotomy (unadjusted effect estimates).

the low number of events, the findings were inconclusive for the following outcomes: chronic pelvic infections, reproductive tract infections, genital infections and vaginitis. However, in adjusted analyses, two studies of low to moderate methodological quality found a statistically higher risk of reproductive tract infections (AOR $=1.54,95 \%$ CI 1.08 to 2.21) and genital infections (AOR $=1.72,95 \%$ CI 1.02 to 2.92 ) with $\mathrm{FGM} / \mathrm{C} .{ }^{37} 43$ Meta-analyses showed a greater risk of urinary tract infections (RR=3.01, 95\% CI 1.42 to 6.38; GRADE: very low; figure 3) $)^{21} 29 \quad 30 \quad 64 \quad 65$ and bacterial vaginosis $(\mathrm{AOR}=1.68,95 \%$ CI 1.28 to 2.22; GRADE: very low) with FGM/C (figure 4). ${ }^{4654}$

\section{Painful sexual intercourse}

Dyspareunia (painful sexual intercourse) was reported in six studies $(\mathrm{n}=6204))^{313354586064}$ The meta-analysis, presented in figure 3, showed an increased risk of dyspareunia with $\mathrm{FGM} / \mathrm{C}(\mathrm{RR}=1.53,95 \%$ CI 1.20 to 1.97 ; GRADE: very low). Correspondingly, results from two nationally representative studies from Eritrea $(n=12$ 540) indicated a 'dose-response' relationship, with a lower risk of problems during sexual relations with FGM/C types I-II relative to type III ( $\mathrm{RR}=0.19$, 95\% CI 0.16 to $0.24 ; \mathrm{RR}=0.44,95 \%$ CI 0.27 to 0.72$).{ }^{34}{ }^{35}$

\section{HIV and sexually transmitted infections}

HIV and sexually transmitted infections (STIs) were clinically examined in one case-control study and 10 crosssectional studies ( $\mathrm{n}=12$ 912).26 32394446525455626371 The case-control study could not establish a difference between $\mathrm{FGM} / \mathrm{C}$ and no $\mathrm{FGM} / \mathrm{C}$ regarding STIs (AOR $=1.13,95 \%$ CI 0.73 to 1.77$).{ }^{32}$ Similarly, the meta-analysis of cross-sectional studies failed to establish a difference $(\mathrm{RR}=1.07,95 \% \mathrm{CI} 0.75$ to 1.53 ; GRADE: very low; figure 3). ${ }^{54} 5571$ As shown in figure 4, also the meta-analysis for HIV, based on four studies which presented adjusted data, failed to establish a difference relative to $\mathrm{FGM} / \mathrm{C} \quad(\mathrm{AOR}=0.95,95 \% \quad \mathrm{CI}=0.54$ to 1.67 ; GRADE: very low). ${ }^{44} 466271$

\section{Infertility}

Twelve studies presented data on infertility (n=36 473). ${ }^{20} 234041464748505464$ Two case-control studies of high methodological quality examined whether FGM/C was a predictor for infertility. The 
Figure 4 Meta-analyses of bacterial vaginosis, HIV, prolonged labour, obstetric tears, caesarean section, instrumental delivery, obstetric haemorrhage, difficult delivery (adjusted effect estimates).

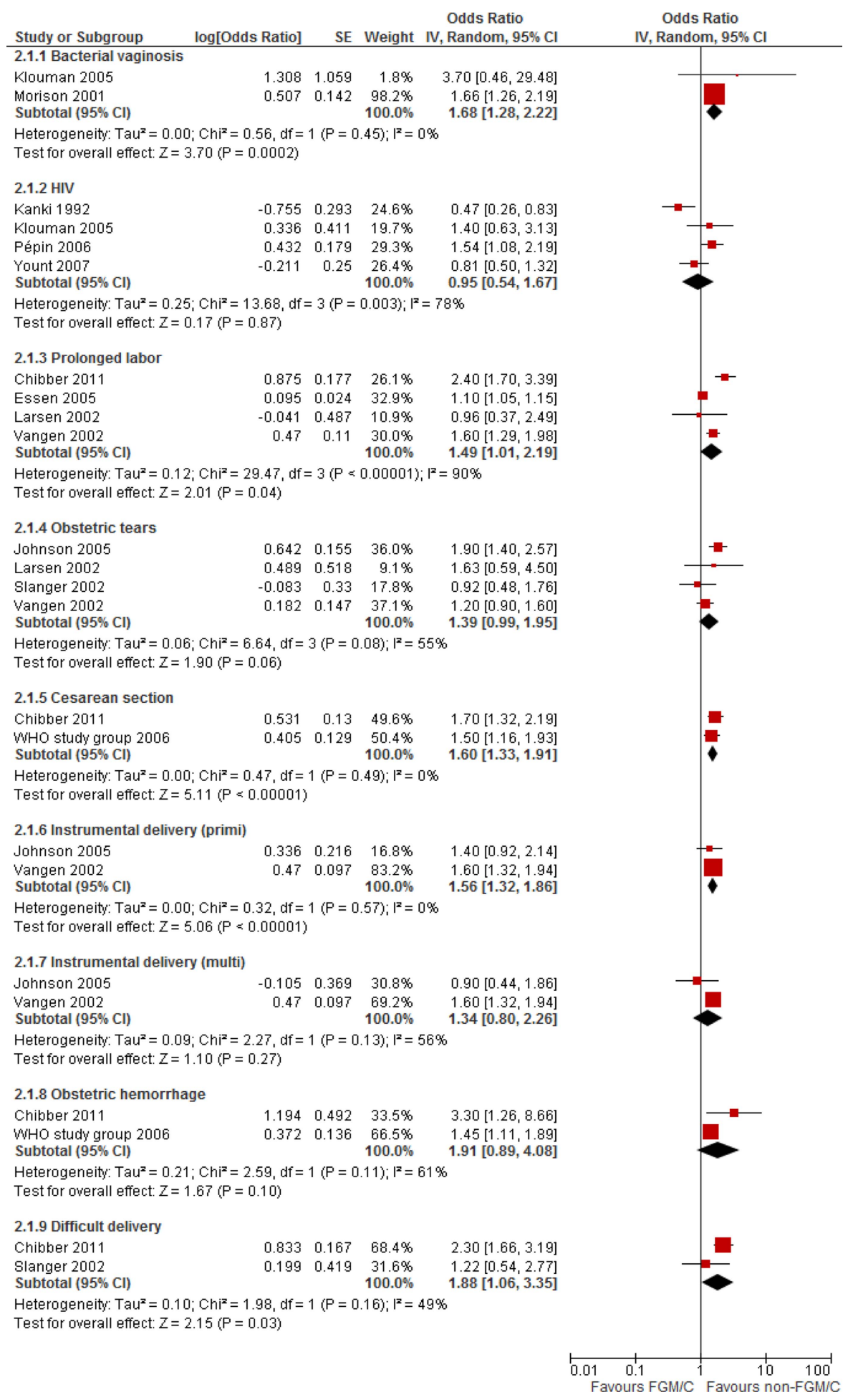

case-control study from Sudan could not establish an association between infertility and FGM/C (AOR=1.77, 95\% CI 0.52 to 7.10$).^{20}$ Similarly, the case-control study from Egypt could not establish a difference between FGM/C type II and type I with respect to tubal factor infertility (AOR $=1.9,95 \%$ CI 0.8 to 4.2$).{ }^{40}$ The available evidence did not allow us to conclude whether women were more likely to be infertile if they were cut by a traditional than a medical circumciser $(\mathrm{AOR}=2.1,95 \%$ CI 0.8 to 5.7$) .{ }^{40}$ Ten cross-sectional studies examined infertility in women with and without FGM/C. The association between FGM/C and infertility varied, both in unadjusted analyses (effect estimates ranged from 0.34 to 3.67 ) and adjusted analyses (AORs from 0.99 to 2.76). Specifically, the results of the two clinical studies of moderate to high methodological quality did not establish a greater risk with FGM/C (OR=1.3, 95\% CI 0.7, 2.7; OR=1.05, 95\% CI 0.65 to 1.67 . Of eight adjusted estimates, two reached significance. These are not shown here because the CIs were not provided in the publications). ${ }^{46} 54$ 


\section{Obstetric outcomes}

Obstetric events (prolonged labour, tears/lacerations, caesarean section, episiotomy, instrumental delivery, haemorrhage, difficult labour) were reported in 26 comparative studies (2.97 million

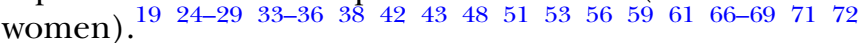
Seven of these were prospective. $\begin{array}{llllllll}24 & 28 & 29 & 43 & 53 & 69 & 70\end{array}$ Eight studies reported adjusted data, with the number and types of confounders varying greatly across studies (detailed in the study under review). ${ }^{2836424348666869}$

Data on prolonged labour were reported in six studies. 282936485368 The meta-analysis of adjusted estimates from four studies showed a significantly greater risk of prolonged labour with FGM/C (AOR=1.49, 95\% CI 1.01 to 2.19; GRADE: low; figure 4). ${ }^{28} 364868$ There was one prospective study, of low to moderate methodological quality, that reported an adjusted estimate for prolonged labour, the result of which was concordant with the meta-analysis $(\mathrm{AOR}=2.40,95 \%$ CI 1.40 to 2.80). ${ }^{28}$ Regarding obstetric tears/lacerations, the meta-analysis of four studies which presented adjusted data showed an AOR of 1.39 (95\% CI 0.99 to 1.95; GRADE: very low; figure 4). ${ }^{42} 486668$ No prospective studies presented adjusted estimates for obstetric tears.

There were 15 studies with data on caesarean section. $^{2425} 28293342485659$ 66-71 Five studies reported adjusted estimates, the pooled estimate of which resulted in an AOR of 1.32 (95\% CI 0.97 to 1.80; GRADE: very low). Restricting the meta-analysis to the two prospective studies established a significant difference between groups (AOR=1.60, 95\% CI 1.33 to 1.91; GRADE: low), indicating a greater risk of caesarean section among women with FGM/C (figure 4). ${ }^{28} 69$ As with the other obstetric outcomes, the study-level results were inconsistent regarding episiotomy. Eleven studies reported on episiotomy, ${ }^{19} 24293338485356666970$ but there was only one (retrospective) study with adjusted data. ${ }^{48}$ The result from the most comprehensive model in this study (ie, adjusting for the highest number of confounders) showed an AOR of 1.18 (95\% CI 0.76 to 1.84$)$. No prospective studies presented adjusted estimates for episiotomy, but we aggregated the unadjusted results from five prospective studies ( $\mathrm{n}=32088$ women $)$, finding an increased risk with $\mathrm{FGM} / \mathrm{C}(\mathrm{RR}=1.38 ; 95 \%$ CI 1.14 to 1.67; GRADE: very low; figure 3). 2429536970

There were nine studies with data on instrumental delivery. $242529425366-6870$ Two (registry based) studies reported adjusted data. ${ }^{42} 68$ The meta-analysis for primiparous women suggested a greater risk of instrumental delivery with FGM/C (AOR=1.56, 95\% CI 1.32 to 1.86 ; GRADE: very low), which could not be firmly established for multiparous women $(\mathrm{AOR}=1.34,95 \%$ CI 0.80 to 2.26; GRADE: very low; figure 4). We also included nine studies with data on obstetric or postpartum haemorrhage. ${ }^{28} 2938425666$ 68-70 Five studies reported adjusted results, which we combined in a meta-analysis. The result indicated a greater risk with $\mathrm{FGM} / \mathrm{C}(\mathrm{AOR}=1.50$,
95\% CI 1.22 to 1.84; GRADE: very low). However, the pooled adjusted estimate based on the two prospective studies that reported adjusted data for haemorrhage failed to establish a convincing difference relative to FGM/C (AOR=1.91, 95\% CI 0.89 to 4.08; GRADE: very low; figure 4). ${ }^{28}$ Lastly, we included six comparative studies with data on difficult delivery. ${ }^{28} 42435666$ The pooled result based on adjusted estimates from the two studies that could be combined resulted in an AOR of 1.88 (95\% CI 1.06 to 3.35; GRADE: low; figure 4). ${ }^{28}{ }^{66} \mathrm{~A}$ third study compared women without FGM/C with women who had FGM/C type I. The AORs were 0.17 $(95 \% \mathrm{CI}=0.06$ to 0.52$)$ and $0.32(95 \% \mathrm{CI}=0.19$ to 0.54$)$, which favoured not having FGM/C. ${ }^{43}$ There was one prospective study with data on difficult delivery. ${ }^{28}$ The estimate showed a greater risk with FGM/C $(\mathrm{AOR}=2.30$, $95 \%$ CI 1.3 to 2.5 ).

\section{DISCUSSION}

This systematic review provides clear evidence that FGM/C entails harms to women's physical health throughout their life, from the moment of cutting as an infant or child, to sexuality and childbirth in adulthood. Predictably, the most common direct, procedure-related complication includes haemorrhage, most likely resulting from laceration of the internal pudendal artery or the clitoral artery. It is difficult to determine the number of females who die from procedure-related complications. Only a few studies reported death, but highly publicised fatalities from FGM/C heighten the awareness of the possible harms posed by the procedure, such as three recent cases in Egypt and Kenya. ${ }^{8-90}$

We found several long-term consequences of FGM/C, including increased risks of urinary tract infections, bacterial vaginosis, dyspareunia and obstetric complications. Studies have been published since we conducted our search, and they corroborate our findings. ${ }^{91-98}$ The identified risks from FGM/C are also supported by biological rationales for the associations. As explained by experts, $^{215492}$ any alteration of the natural anatomy of the vulva, such as removal of the protective labia minora, can lead to structural and physiological changes, including trauma to the urethra, adjacent tissues and nerves at the time of the procedure as well as formation of scars and flaps of skin during the healing process.

FGM/C is a non-therapeutic procedure, which by definition does not treat an underlying pathological process, but rather forms an actionable risk factor for several morbidities. As public policy discussions gain momentum on how to prevent FGM/C, our findings about the health complications could be communicated to practising communities, health practitioners, government bodies, international health organisations and other stakeholders. Global policy efforts should be expended in safeguarding females against the physical risks of FGM/C and, as emphasised by the United Nations agencies, ${ }^{1}$ in upholding their bodily integrity 
and furthering their human rights. Worldwide, about 125 million girls and women alive today live with FGM/C, and every year another three million girls in the countries where the practice is concentrated are at risk of undergoing the practice. ${ }^{2}{ }^{99}$ Caring for girls and women who suffer from its consequences and research into the best and most acceptable treatment and care are important.

This systematic review offers the most comprehensive and scientific evidence presently available on the range of physical health complications from $\mathrm{FGM} / \mathrm{C}$-other reviews are non-systematic and limited in scope ${ }^{4-7}$-but a complete understanding is hindered by data gaps. The search was executed in 2012 and it is possible that our systematic review is subject to publication bias. The discrepancy between the large number of records identified in our search and the 185 studies included attest to the literature on FGM/C being longer on opinion and polemic and considerably shorter on data. We identified only three case-control studies and seven prospective studies. Many included studies had low methodological study quality; many outcomes were reported in just a few studies, and event rates in several studies were low. Thus, most data are of low quality, which partly results from the nature of the study question, which is difficult to answer by means of rigorous research methods. Additionally, the measurement and reporting of exposure, outcome and confounders were done with varying precision in the included studies, and although we did subgroup and random-effects analyses, these could not fully account for the observed heterogeneity across studies. Thus, the summary estimates for all outcomes should be interpreted cautiously. Some of the above possible sources of biases would tend to bias our summary estimates towards the null, and are likely to lead to too conservative estimates of the true harmful association of FGM/C with physical health. For example, research on male circumcision has found that adverse events are recorded less frequently in retrospective than prospective studies. ${ }^{100}$ Owing to gaps in the evidence base, precise estimation of frequency and risk of complications is not possible. However, irrespective of the exact size of the greater risk from FGM/C, the consistency of results with increased risk of several physical harms in women with genital modification is robust, and even the lowest increase in risk of complications is undesirable from a woman's health perspective.

\section{CONCLUSION}

The evidence base on the physical health complications of FGM/C, which covers over half a century of research from more than 20 countries in Africa and beyond, shows that FGM/C is associated with an increased risk of health complications, especially urinary tract infections, bacterial vaginosis, painful sexual intercourse and obstetric difficulties. Further research into this question is unlikely to produce practical value. Rather, efforts should be expended in safeguarding girls and women against the physical risks of FGM/C and caring for those who suffer from its consequences.

Acknowledgements The authors gratefully acknowledge the support and financial assistance received from Norad and the WHO. They are also grateful to librarian Sari S. Ormstaad who designed and conducted the literature search and to the experts who reviewed early versions of our technical reports.

Contributors RCB planned the study; collected, analysed, and synthesised the data; and wrote the article. VU assisted in data collection and synthesis; and contributed to the writing of the article. GEV and AF assisted in data synthesis and contributed to the writing of the article. J0-J assisted in data analysis and contributed to the writing of the article.

Funding This research received no specific grant from any funding agency in the public, commercial or not-for-profit sectors.

\section{Competing interests None.}

Provenance and peer review Not commissioned; externally peer reviewed.

Data sharing statement Three technical reports available for all at http:// www.kunnskapssenteret.no/publikasjoner.

Open Access This is an Open Access article distributed in accordance with the Creative Commons Attribution Non Commercial (CC BY-NC 4.0) license, which permits others to distribute, remix, adapt, build upon this work noncommercially, and license their derivative works on different terms, provided the original work is properly cited and the use is non-commercial. See: http:// creativecommons.org/licenses/by-nc/4.0/

\section{REFERENCES}

1. WHO. Eliminating female genital mutilation: an interagency statement. Geneva: World Health Organization, 2008.

2. UNICEF. Female genital mutilation/cutting: a statistical overview and exploration of the dynamics of change. New York: UNICEF, 2013.

3. Wade LD. Ideological context and the framing of female genital mutilation. Paper presented 2005-08-12 at the annual meeting of the American Sociological Association; Philadelphia, 2000. http:// citation.allacademic.com/meta/p20640_index.htmIWHO (accessed 26 Jul 2013)

4. Obermeyer CM, Reynolds RF. Female genital surgeries, reproductive health and sexuality: a review of the evidence. Reprod Health Matters 1999;7:112-20.

5. Obermeyer CM. The consequences of female circumcision for health and sexuality: an update on the evidence. Cult Health Sex 2005;7:443-61.

6. WHO. A systematic review of the health complications of female genital mutilation including sequelae in childbirth. Geneva: World Health Organization, 2000.

7. lavazzo C, Sardi TA, Gkegkes ID. Female genital mutilation and infections: a systematic review of the clinical evidence. Arch Gynecol Obstet 2013;287:1137-49.

8. Berg RC, Denison E. Psychological, social and sexual consequences of female genital mutilation/cutting (FGM/C): a systematic review of quantitative studies. Oslo: Norwegian Knowledge Center for the Health Services (NOKC); 2013, Report No: 6.

9. Berg RC, Denison E. Does female genital mutilation/cutting (FGM/ C) affect women's sexual functioning? A systematic review of the sexual consequences of FGM/C. Sex Res Soc Pol 2012;9:41-56.

10. The Public Policy Advisory Network on Female Genital Surgeries in Africa. Seven things to know about female genital surgeries in Africa. Hastings Cent Rep 2012;42:19-27.

11. Berg RC, Underland V. Obstetric consequences of female genital mutilation/cutting (FGM/C). Oslo: Norwegian Knowledge Center for the Health Services (NOKC); 2013, Report No: 6.

12. Berg RC, Underland V. Immediate health consequences of female genital mutilation/cutting (FGM/C). Oslo: Norwegian Knowledge Center for the Health Services (NOKC); 2014, Report No: 8

13. Berg RC, Underland V. Gynecological consequences of female genital mutilation/cutting (FGM/C). Oslo: Norwegian Knowledge Center for the Health Services (NOKC); 2014; Report No: 11. 
14. Higgins JPT, Green S, eds. Cochrane handbook for systematic reviews of interventions. Version 5.1.0. The Cochrane Collaboration, 2011

15. Moher D, Liberati A, Tetzlaff J, et al. The PRISMA Group. Preferred reporting items for systematic reviews and meta-analyses: The PRISMA statement. PLoS Med 2009;6:doi: 10.1371/journal. pmed1000097

16. Guyatt G, Rennie D, Mead MO, et al. User's guides to the medical literature, a manual for evidence-based clinical practice. 2nd edn. New York: The McGraw-Hill Companies, Inc, 2008.

17. Guyatt GH, Oxman AA, Akl E, et al. GRADE guidelines 1. Introduction-GRADE evidence profiles and summary of findings tables. J Clin Epidemiol 2011;64:383-94.

18. Berlin JA; for the University of Pennsylvania Meta-analysis Blinding Study Group. Does blinding of readers affect the results of meta-analyses? Lancet 1997;350:185-6.

19. Adinma Jl. Current status of female circumcision among Nigerian Igbos. West Afr J Med 1997;16:227-31.

20. Almroth L, Elmusharaf S, El Hadi N, et al. Primary infertility after genital mutilation in girlhood in Sudan: a case-control study. Lancet 2005;366:385-91.

21. Almroth L, Bedri $\mathrm{H}$, El Musharaf $\mathrm{S}$, et al. Urogenital complications among girls with genital mutilation: a hospital based study in Khartoum. Afr J Reprod Health 2005;9:118-24.

22. Alsibiani S, Rouzi AA. Sexual functioning in women with female genital mutilation. Fertil Steril 2010;93:722-4.

23. Balk D. To marry and bear children? The demographic consequences of infibulation in Sudan. In: Shell-Duncan B, Hernlund Y, eds. Female 'circumcision' in Africa. Culture, controversy and change. London: Lynne Rieneuer Publishers, 2000:55-71.

24. Berardi JC, Teillet JF, Godard J, et al. Consequences obstetricales de l'excision feminine. Etude chez 71 femmes africaines excisees. J Gynecol Obstet Biol Reprod 1985;14:743-6.

25. Bohoussou KM, Anongba S, Djanhan Y, et al. Complications gynecologiques medicales et obstetricales de l'excision rituelle. Afr Med 1986;25:160-2.

26. Brewer DD, Potterat JJ, Roberts JM Jr, et al. Male and female circumcision associated with prevalent HIV infection in virgins and adolescents in Kenya, Lesotho, and Tanzania. Ann Epidemiol 2007; $17: 217-26$

27. Browning A, Allsworth JE, Wall LL. The relationship between female genital cutting and obstetric fistulae. Obstet Gynecol 2010;115:578-83.

28. Chibber R, El-Saleh E, El Harmi J. Female circumcision: obstetrical and psychological sequelae continues unabated in the $21 \mathrm{st}$ century. J Matern Fetal Neonatal Med 2011;24:833-6.

29. De Silva S. Obstetric sequelae of female circumcision. Eur J Obstet Gynecol Reprod Biol 1989;32:233-40.

30. El Dareer A. Complications of female circumcision in the Sudan. Trop Doct 1983;13:131-3.

31. el Defrawi MH, Lotfy G, Dandash KF, et al. Female genital mutilation and its psychosexual impact. $J$ Sex Marital Ther 2001;27:465-73.

32. Elmusharaf S, Elkhidir I, Hoffmann S, et al. A case-control study on the association between female genital mutilation and sexually transmitted infections in Sudan. BJOG 2006;113:469-74.

33. Elnashar A, Abdelhady R. The impact of female genital cutting on health of newly married women. Int J Gynaecol Obstet 2007;97:238-44.

34. National Statistics and Evaluation Office (NSEO), ORC Macro. Eritrea demographic and health survey 2002. Calverton, Maryland: NSEO, ORC Macro, 2003.

35. National Statistics Office (NSO). Macro International. Eritrea demographic and health survey 1995. Calverton, Maryland: NSO, Macro International, 1997.

36. Essen B, Sjöberg NO, Gudmundsson S, et al. No association between female circumcision and prolonged labour: a case control study of immigrant women giving birth in Sweden. Eur J Obstet Gynec Reprod Biol 2005;121:182-5.

37. Fillo GF, Leone T. Female genital cutting, reproductive tract infections and perinatal outcome in Burkina Faso. Paper presented 2007-3-29 at the Annual Meeting of the Population Association of America; New York.

38. Hakim LY. Impact of female genital mutilation on maternal and neonatal outcomes during parturition. East Afr Med J 2001;78:255-8.

39. Holmgren B, da Silva Z, Larsen O, et al. Dual infections with HIV-1, HIV-2 and HTLV-I are more common in older women than in men in Guinea-Bissau. AIDS 2003;17:241-53.
40. Inhorn MC, Buss KA. Infertility, infection, and iatrogenesis in Egypt the anthropological epidemiology of blocked tubes. Med Anthropol 1993;15:217-44

41. Jackson EF, Adongo PB, Bawah AA, et al. The relationship between female genital cutting and fertility in Kassena-Nankana District of Northern Ghana. Paper presented 2005-3-31 at the Annual Meeting of the Population Association of America; Philadelphia.

42. Johnson EB, Reed SD, Hitti J, et al. Increased risk of adverse pregnancy outcome among Somali immigrants in Washington state. Am J Obstet Gynecol 2005;193:475-82.

43. Jones H, Diop N, Askew I, et al. Female genital cutting practices in Burkina Faso and Mali and their negative health outcomes. Stud Fam Plann 1999;30:219-30

44. Kanki $P$, M'Boup S, Marlink $R$, et al. Prevalence and risk determinants of human immunodeficiency virus type 2 (HIV-2) and human immunodeficiency virus type 1 (HIV-1) in west African female prostitutes. Am J Epidemiol 1992;136:895-907.

45. Kaplan A, Hechavarria S, Martin M, et al. Health consequences of female genital mutilation/cutting in the Gambia, evidence into action. Reprod Health 2011;8:26.

46. Klouman E, Manongi R, Klepp K-I. Self-reported and observed female genital cutting in rural Tanzania: associated demographic factors, HIV and sexually transmitted infections. Trop Med Int Health 2005;10:105-15.

47. Larsen $U$. The effects of type of female circumcision on infertility and fertility in Sudan. J Biosoc Sci 2002;34:363-77.

48. Larsen U, Okonofua FE. Female circumcision and obstetric complications. Int J Gynaecol Obstet 2002;77:255-65.

49. Larsen $U$, Yan $S$. Does female circumcision affect infertility and fertility? A study of the Central African Republic, Cote d'Ivoire, and Tanzania. Demography 2000;37:313-21.

50. Larsen U. A comparative study of the levels and differentials of sterility in Cameroon, Kenya and Sudan. In: Lesthaeghe RJ. ed. Reproduction and social organization in Sub-Saharan Africa. London: University of California Press, 1989:167-211.

51. Lupo VR, Marcotte KL. Obstetric complications of Somali female circumcision. Obstet Gynecol 1999;93:19S

52. Maslovskaya O, Brown JJ, Padmadas SS. Disentangling the complex association between female genital cutting and HIV among Kenyan women. J Biosoc Sci 2009;41:815-30.

53. Millogo-Traore F, Kaba ST, Thieba B, et al. Pronostic maternel et foetal au cours de l'accouchement chez la femme excisee. J Gynecol Obstet Biol Reprod 2007;36:393-8.

54. Morison L, Scherf C, Ekpo G, et al. The long-term reproductive health consequences of female genital cutting in rural Gambia: a community-based survey. Trop Med Int Health 2001;6:643-53.

55. Msuya SE, Mbizvo E, Hussain A, et al. Female genital cutting in Kilimanjaro, Tanzania: changing attitudes? Trop Med Int Health 2002;7:159-65.

56. Ndiaye $\mathrm{P}$, Diongue $\mathrm{M}$, Faye $\mathrm{A}$, et al. Mutilation genitale femminine et complications de l'accouchement dans la province de Gourma (Burkina Faso). Sante Publique 2010:22:563-70.

57. Nwajei SD, Otiono Al. Female genital mutilation: implications for female sexuality. Women Stud Int Forum 2003;26:575-80.

58. Odoi A, Brody SP, Elkins TE. Female genital mutilation in rural Ghana, West Africa. Int J Gynaecol Obstet 1997;56:179-80.

59. Oduro A, Ansah P, Hodgson A, et al. Trends in the prevalence of female genital mutilation and its effect on delivery outcomes in the Kassena-Aankana district of northern Ghana. Ghana Med J 2006:40:87-92.

60. Okonofu FE, Larsen U, Oronsaye F, et al. The association between female genital cutting and correlates of sexual and gynaecological morbidity in Edo State, Nigeria. BJOG 2002;109:1089-96.

61. Orji EO, Babalola A. Correlates of female genital mutilation and its impact on safe motherhood. JTGGA 2006;7:319-24.

62. Pepin J, Plamondon M, Alves AC, et al. Parenteral transmission during excision and treatment of tuberculosis and trypanosomiasis may be responsible for the HIV-2 epidemic in Guinea-Bissau. AIDS 2006;20:1303-11.

63. Pepin J, Dunn D, Gaye I, et al. HIV-2 infection among prostitutes working in The Gambia: association with serological evidence of genital ulcer diseases and with generalized lymphadenopathy. AIDS 1991:5:69-75.

64. Rushwan H, Slot CJM, El Dareer A, et al. Female circumcision in the Sudan. Prevalence, complications, attitudes and change. A report of a study conducted by the faculty of medicine, University of Khartoum, Sudan (1977-1982). Khartoum: University of Khartoum, 1983. 
65. Shandall AA. Circumcision and infibulation of females: a general consideration of the problem and a clinical study of the complications in Sudanese women. Sudan Med J 1967;5:178-212.

66. Slanger TE, Snow RC, Okonofua FE. The impact of female genital cutting on first delivery in southwest Nigeria. Stud Fam Plann 2002;33:173-84.

67. Small R, Gagnon A, Gissler M, et al. Somali women and their pregnancy outcomes postmigration: data from six receiving countries. BJOG 2008;115:1630-40.

68. Vangen S, Stoltenberg C, Johansen RE, et al. Perinatal complications among ethnic Somalis in Norway. Acta Obstet Gynecol Scand 2002;81:317-22.

69. WHO study group on female genital mutilation and obstetric outcomeBanks E, Meirik O, Farley T et al. Female genital mutilation and obstetric outcome: WHO collaborative prospective study in six African countries. Lancet 2006;367:1835-41.

70. Wuest $S$, Raio L, Wyssmueller $D$, et al. Effects of female genital mutilation on birth outcomes in Switzerland. BJOG 2009;116:1204-9.

71. Yount KM, Abraham BK. Female genital cutting and HIV/AIDS among Kenyan women. Stud Fam Plann 2007;38:73-88.

72. Yount KM, Carrera JS. Female genital cutting and reproductive experience in Minya, Egypt. Med Anthropol Q 2006;20:182-211.

73. Institut National de la Stastique, de Études Économiques et Démographiques (INSEED). Ministère de l'Économie, du Plan et de la Coopération, ORC Macro. Enquête démographique et de santé Tchad 2004. Calverton, Maryland: INSEED, ORC Macro, 2005.

74. Ministère de l'Économie, du Plan et de la Coopération Internationale, Macro International Inc. Enquête démographique et de santé, République Centrafrieaine 1994-95. Calverton, Maryland Direction des Statistiques Démographiques et Sociales, Macro International Inc, 1995.

75. Asuen MI. Maternal septicaemia and death after circumcision. Trop Doc 1977;7:177-8.

76. Badejo OA. Complications of circumcision: the lfe experience. Nigerian Med Pract 1983;5:103-9.

77. Osifo DO, Evbuomwan I. Female genital mutilation among Edo people: the complications and patterns of presentation at a pediatic surgery unit, Benin City. Afr J Reprod Health 2009;13:17-25.

78. Institut National de la Statistique et de l'Analyse Economique (INSAE). ORC Macro. Enquête démographique et de santé au Bénin 2001. Calverton, Maryland: INSAE, ORC Macro, 2002.

79. Institut National de la Statistique et de la Demographie (INSD). Ministere de l'economie et du Developpement, ORC Macro. Enquête démographique et de santé du Burkina Faso 2003. Calverton, Maryland: INSD, ORC Macro, 2004.

80. Direction Nationale de la Statistique (DNS), Ministère du Plan Conakry. ORC Macro. Enquête démographique et de santé, Guinée 2005. Calverton, Maryland: DNS, ORC Macro, 2006.

81. Direction Nationale de la Statistique, Minstère du Plan et de la Coopération. Macro International Inc. Enquête démographique et de santé, Guinée 1999. Calverton, Maryland: Direction Nationale de la Statistique, Macro International Inc, 2000.

82. Cellule de Planification et de Statistique du Ministère de la Santé (CPS/MS). Direction Nationale de la Statistique et de l'Informatique (DNSI), ORC Macro. Enquête démographique et de santé au Mali 2001. Calverton, Maryland: CPS/MS, DNSI, ORC Macro, 2002.

83. Cellule de Planification et de Statistique du Ministère de la Santé (CPS/MS), Direction Nationale de la Statistique et de l'Informatique
(DNSI), ORC Macro. Enquête démographique et de santé au Mali 2001. Calverton, Maryland: CPS/MS, DNSI, ORC Macro; 2002.

84. Cellule de Planification et de Statistique du Ministère de la Santé (CPS/MS), Direction Nationale de la Statistique et de l'Informatique du Ministère de l'Économie, de l'Industrie et du Commerce (DNSI/ MEIC), Macro International Inc. Enquête démographique et de santé du Mali 2006. Calverton, Maryland: CPS/DNSI, Macro International Inc, 2007.

85. Mandara MU. Female genital mutilation in Nigeria. Int $J$ Gynaecol Obstet 2004;84:291-8.

86. Office National de la Statistique (ONS). ORC Macro. Enquête démographique et de santé Mauritanie 2000-2001. Calverton, Maryland: ONS, ORC Macro, 2001.

87. Ndiaye S, Ayad M. Enquête démographique et de santé au Sénégal 2005. Calverton, Maryland: Centre de Recherche pour le Développement Humain, ORC Macro, 2006.

88. Black I. Egypt bans female circumcision after death of a 12-year-old girl. The Guardian 30 June 2007. http://www. theguardian.com/world/2007/jun/30/gender.humanrights (accessed 17 May 2014).

89. Trew B. Unkindest cut: 13-year-old's death shines spotlight on rise of FGM in Egypt. London Evening Standard 13 June 2013. http:// www.standard.co.uk/lifestyle/london-life/unkindest-cut-13yearoldsdeath-shines-spotlight-on-rise-of-fgm-in-egypt-8657104.html (accessed 17 May 2014).

90. Migiro K. Kenya: two to be charged with murder after Kenyan FGM victim dies. AlertNet 2014, 23 April. http://www.news.nom.co/ kenya-murder-charges-after-kenyan-9154121-news/ (accessed 17 May 2014).

91. Abdulcadir J, Dällenbach P. Overactive bladder after female genital mutilation/cutting (FGM/C). BMJ Case Rep 2013;2013:pii: bcr2012008155.

92. Amin MM, Rasheed S, Salem E. Lower urinary tract symptoms following female genital mutilation. Int J Gynaecol Obstet 2013;123:21-3.

93. Andersson SHA, Rymer J, Joyce DW, et al. Sexual quality of life in women who have undergone female genital mutilation: a case-control study. BJOG 2012;119:1606-11.

94. Andro A, Cambois E, Lesclingand M. Long-term consequences of female genital mutilation in a European context: self perceived health of FGM women compared to non-FGM women. Soc Sci Med 2014:106:177-84.

95. Anis TH, Gheit SA, Awad HH, et al. Effects of female genital cutting on the sexual function of Egyptian women. A cross sectional study. J Sex Med 2012;9:2682-92.

96. Berggren V, Gottvall K, Isman E, et al. Infibulated women have an increased risk of anal sphincter tears at delivery: a population-based Swedish register study of 25000 births. Acta Obstet Gynecol Scand 2013;92:101-8.

97. Diouf K, Nour N. Female genital cutting and HIV transmission: is there an association? Am J Reprod Immunol 2013;69(Suppl):45-50.

98. Zayed AA, Ali AA. Abusing female children by circumcision is continued in Egypt. J Forensic Leg Med 2012;19:196-200.

99. Yoder S, Kahn S. Numbers of women circumcised in Africa: the production of a total. United States Agency for International Development; 2008, Report No: 39.

100. Weiss HA, Larke N, Halperin D, et al. Complications of circumcision in male neonates, infants and children: a systematic review. BMC Urol 2010;10:2. 